\title{
Visceral brown fat necrosis in postperinatal mortality
}

\author{
T J STEPHENSON, S VARIEND \\ From the Department of Histopathology, Children's Hospital, Western Bank, Sheffield
}

\begin{abstract}
SUMMARY Fat necrosis was present in 22 of 400 cases of consecutive postperinatal mortalities investigated to assess the presence and pattern of deep fat necrosis. In just over $50 \%$ of the cases of fat necrosis the cause of death was categorised as sudden infant death syndrome, which also showed more severe degrees of necrosis. The mechanism of necrosis may be vascular hypoperfusion, possibly related to shock, and brown adipose tissue, on account of its high metabolic activity and rich capillary plexus, may be particularly vulnerable to infarction. The occurrence of fat necrosis in association with other causes of death did not provide any definite clue as to the nature of the alleged shock.
\end{abstract}

Fat necrosis, or panniculitis, usually occurs in a wide range of surgical or accidental conditions. WeberChristian disease is the most well documented of the panniculitides. ${ }^{1}$ While its pathogenesis is scarcely understood, it has been associated with diverse aetiologies, including physical and chemical injuries, immunological disorders, infection, pancreatic disease, possible nutritional deficiencies, hyperlipidaemia and idiopathic orders. ${ }^{2}$ This form of lobular panniculitis usually affects the subcutaneous adipose tissue, but occasionally the disease may extend to visceral adipose tissue. ${ }^{3}$ The condition has been described in infants. ${ }^{4}$

We report the presence of lobular fat necrosis in brown adipose tissue of deep sites in a series of postperinatal necropsies, paying particular reference to the association with sudden infant death syndrome (SIDS).

\section{Material and methods}

Four hundred consecutive postperinatal deaths occurring from September 1980 to November 1986 and aged between 1 week and 2 years were investigated. Two hundred and eighty seven were categorised as SIDS; 64 were associated with congenital malformation; 23 were related to infection; and there were 26 associated with neoplasm and trauma. Of the 64 with congenital malformation, 23 had congenital heart disease. The reason for the large proportion of cases of SIDS is that in addition to necropsies at our

Accepted for publication 19 March 1987 own hospital, our department also carries out necropsies for a large area (South Yorkshire) in cases of sudden death at home, whereas other deaths are dealt with at individual hospitals by the respective pathologists.

Standardised blocks were taken through the centre of both adrenals and through the midpoint of the trachea ensuring that reasonable amounts of adjoining fat were included. Sections were stained with haematoxylin and eosin and examined microscopically. Immunoperoxidase staining for $\alpha$-1-antitrypsin and an $\alpha$-naphthyl-ASD-chloracetate esterase (Leder's) stain were used in some instances to assist in the identification of macrophages and to highlight neutrophils, respectively.

The nature and extent of the inflammatory response within lobules of adipose tissue were recorded, as were any other abnormal microscopic findings. The occurrence of fat necrosis was subsequently compared with cause of death. The definition of SIDS was that originally proposed by Beckwith, ${ }^{5}$ but those infants found moribund at home and subjected to variable periods of ventilator support were also included in this category.

\section{Results}

Inflammation varied from mild changes affecting only a few pannicles (fig 1) to severe necrosis with accompanying inflammation (fig 2 ) affecting several pannicles. Macrophages were the most common cellular response (table 1) and the central portion of the pannicle was often affected (figs 3 and 4). There were no multinuclear forms and the cytoplasm was not foamy. 
Table 1 Type (and severity) of histological changes in visceral brown fat

\begin{tabular}{lllll}
\hline & Neutrophils & Macrophages & Fibrosis & Calcification \\
\hline SIDS & $3(1)$ & $7(6)$ & 1 & 1 \\
Congenital heart disease & 2 & $2(1)$ & 1 & \\
Others & $5(1)$ & $5(2)$ & 2 & 1 \\
Total & $14(9)$ & & \\
\hline
\end{tabular}

Irregular fibrosis (fig 5) was seen in two cases in the periadrenal location, one occurring in a case of congenital heart disease and another in a child dying with Smith-Lemli-Opitz syndrome. One case of SIDS showed dystrophic calcification (fig 6) affecting both sites, accompanied by a mild inflammatory infiltration. Granulomata or crystallisation of lipid were not seen, and there was no microscopic evidence of a vas-

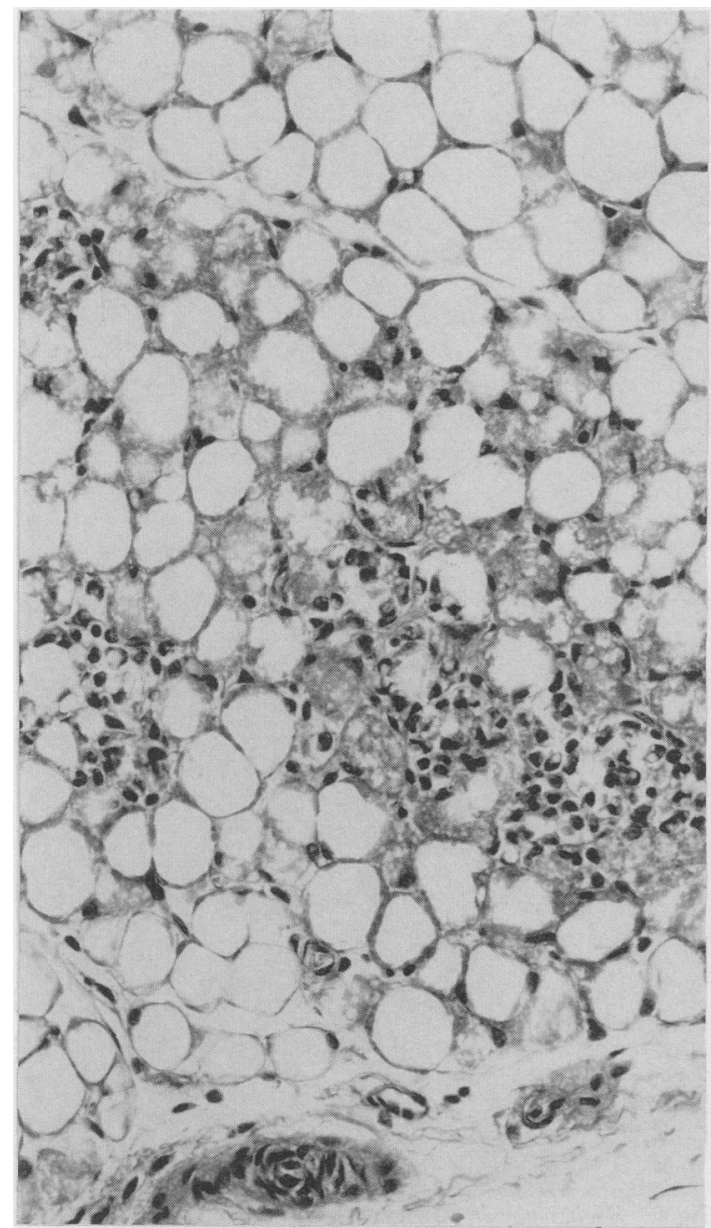

Fig 1 Few neutrophils are seen within lobule of periadrenal brown adipose tissue (Haematoxylin and eosin.) culitis. Fat necrosis was seen in 16 cases in the periadrenal adipose tissue and in 12 cases in the peritracheal adipose tissue. In six cases both sites were affected. Hence the total number of postperinatal deaths showing fat necrosis was $22(5 \%)$.

Eleven cases occurred in babies with SIDS (age range: $1-4$ months), representing $4 \%$ of the total SIDS group; two died after initial resuscitation and

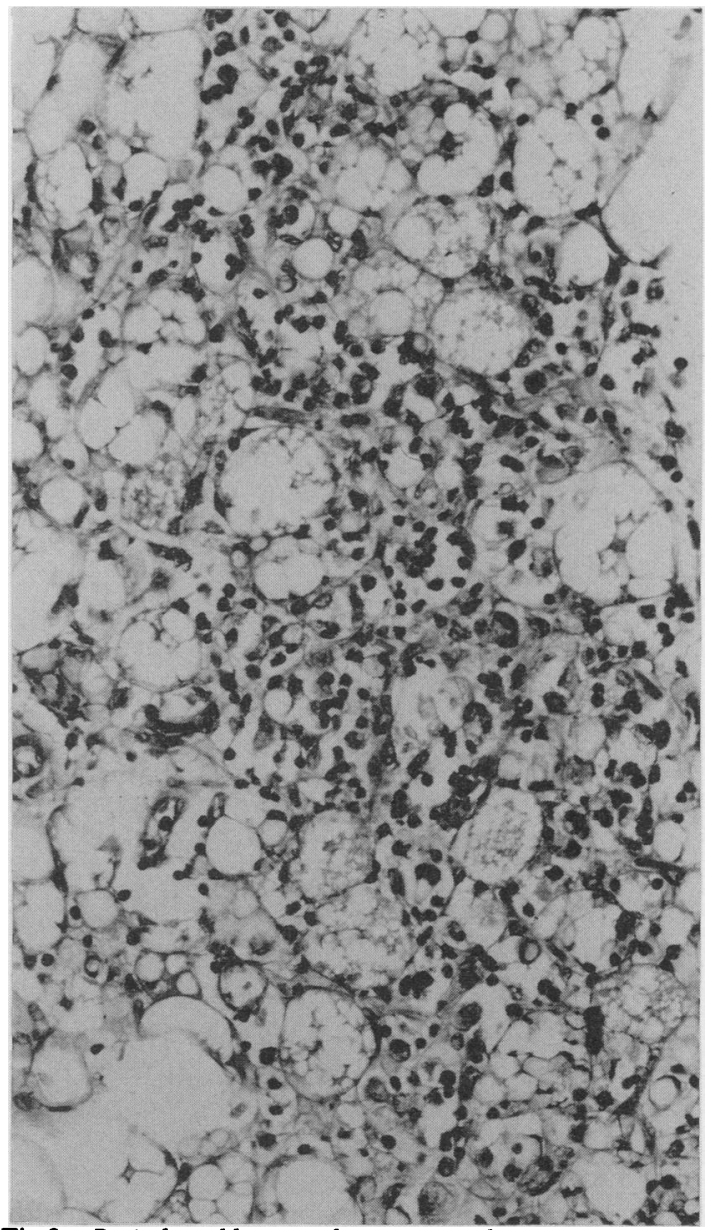

Fig 2 Periadrenal brown adipose tissue showing severe necrosis and appreciable neutrophil infiltration (Haematoxylin and eosin.) 
Table 2 Miscellaneous category showing visceral fat necrosis

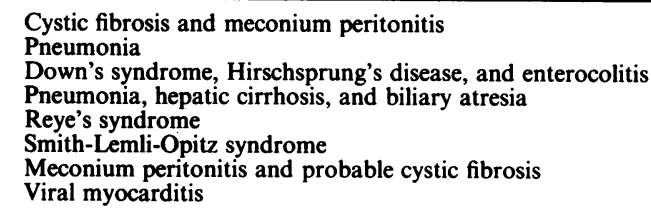

ventilator support for eight and five days, respectively. Three cases occurred in association with severe congenital heart disease, which included transposition of the great vessels with previous balloon

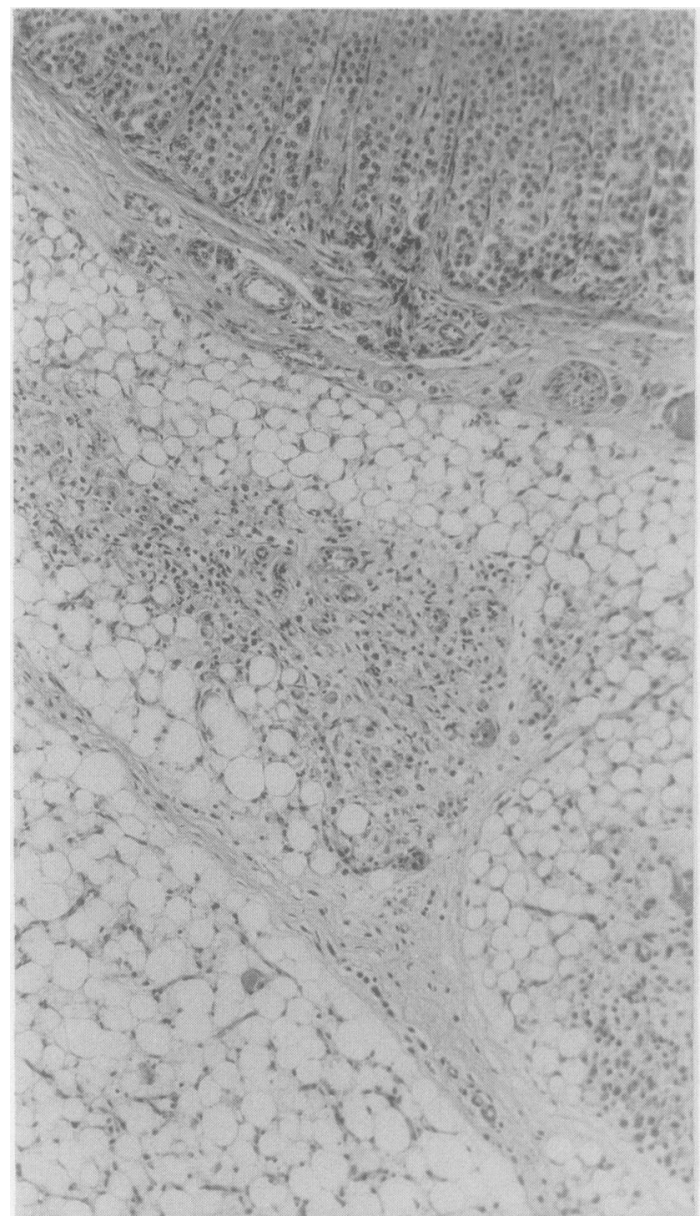

Fig 3 Lobule of periadrenal brown adipose tissue with early central fibrosis and macrophage response. Part of adjacent lobule of adipose tissue similarly affected is seen in left lower field. Adrenal gland is at top (Haematoxylin and eosin.) septostomy, double outlet right ventricle, and one with a patent ductus arteriosus, ventricular, and atrial septal defect (age range: 2 weeks -9 months). Thus $13 \%$ of the total number of infants with congenital heart disease showed fat necrosis. In the remainder the cause of death was widely variable (age range: 3 weeks-16 months) (table 2).

Among those cases in whom periadrenal and peritracheal sites were affected, all except one occurred in SIDS (table 3 ). The one exception was a 3 week old baby dying with cystic fibrosis and meconium peritonitis; the terminal event was thought to be septicaemia. Five of the remaining six cases of SIDS showed fat necrosis limited to the periadrenal tissue.

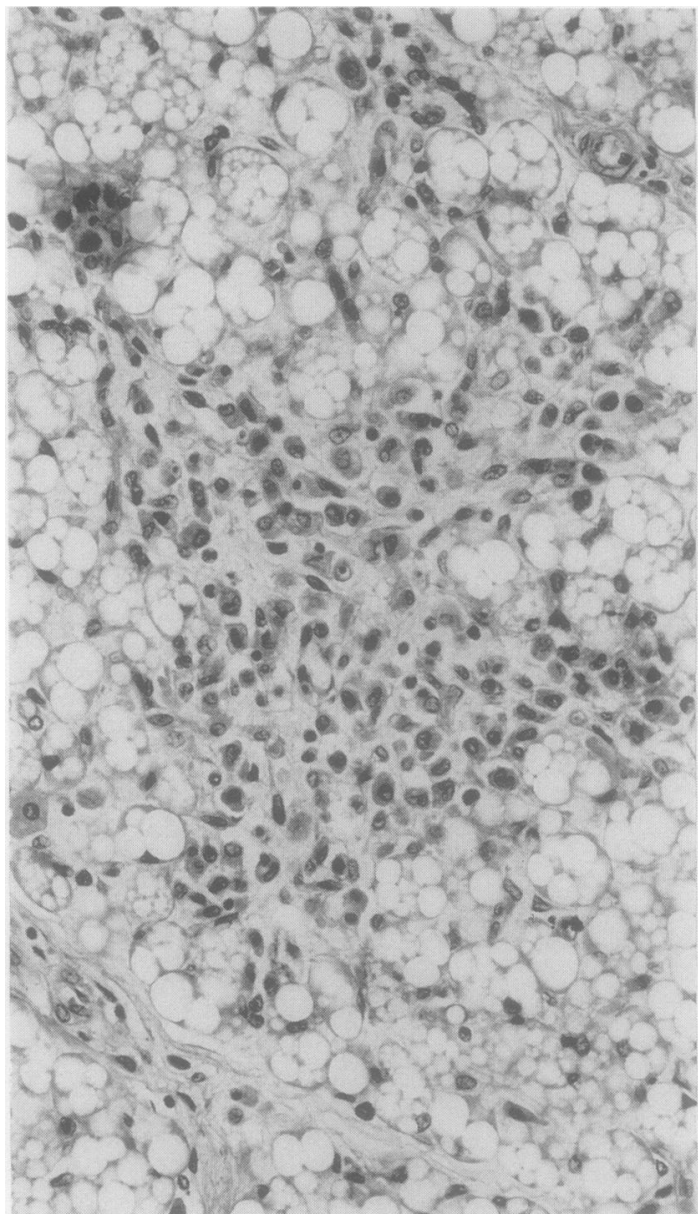

Fig 4 Higher power view to show presence of macrophages within centre of lobule of adipose tissue (Haematoxylin and eosin.) 
Table 3 Distribution of visceral fat necrosis

\begin{tabular}{llll}
\hline & $\begin{array}{l}\text { Periadrenal disease } \\
\text { Peritracheal disease }\end{array}$ & $\begin{array}{l}\text { Periadrenal disease } \\
\text { only }\end{array}$ & Peritracheal disease only \\
\hline SIDS & 5 & 5 & 1 \\
Congenital heart disease & 0 & 2 & 1 \\
Other & 1 & 3 & 4 \\
Total & 6 & 10 & 6 \\
\hline
\end{tabular}

Only one showed peritracheal disease. The group with congenital heart disease and other deaths had no particular site affected. Generally, the periadrenal adipose tissue was more severely affected than that in the peritracheal site. The most pronounced changes occurred among those dying of SIDS: thus of the 10 cases showing the most severe necrosis seven were in this group (table 1).

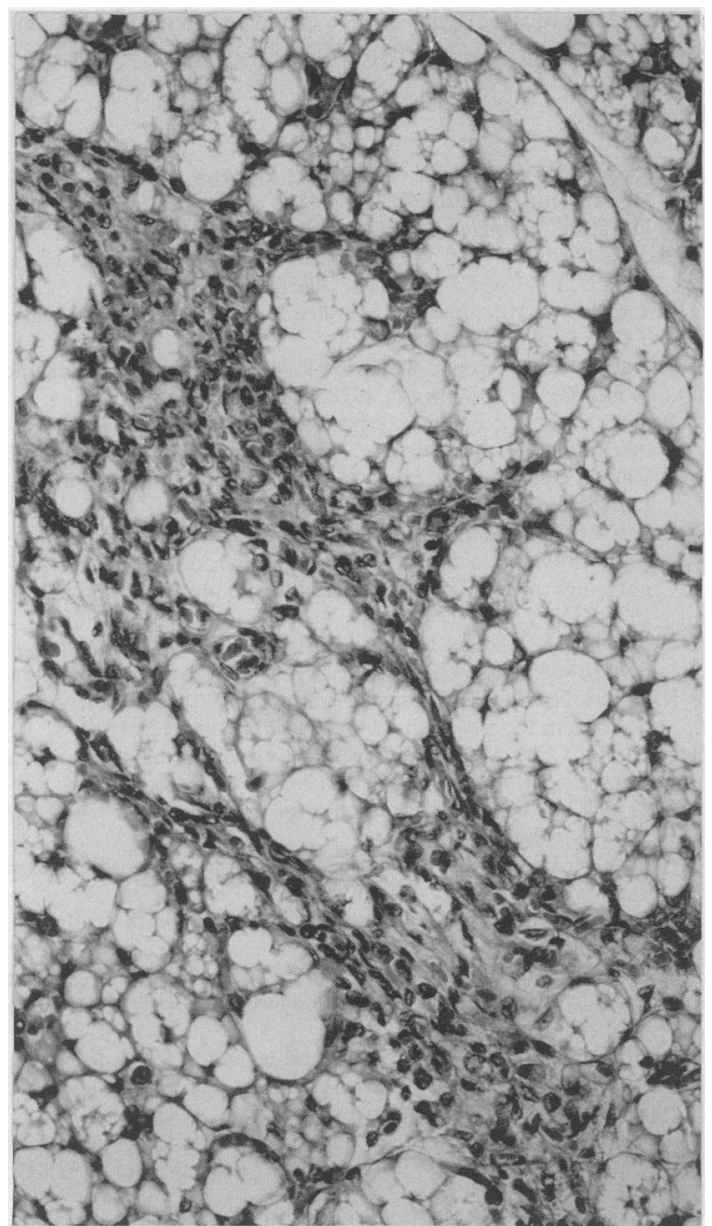

Fig 5 Lobule of brown fat with central irregular area of fibroblastic tissue (Haematoxylin and eosin.)

\section{Discussion}

A similar spectrum of changes to those found in the present study occurs in the lobular panniculitis of Weber-Christian disease. ${ }^{6}$ These changes are thought to represent different stages in the evolution of a common lesion and, with some degree of overlap, are characterised by neutrophilic infiltration, a histio-

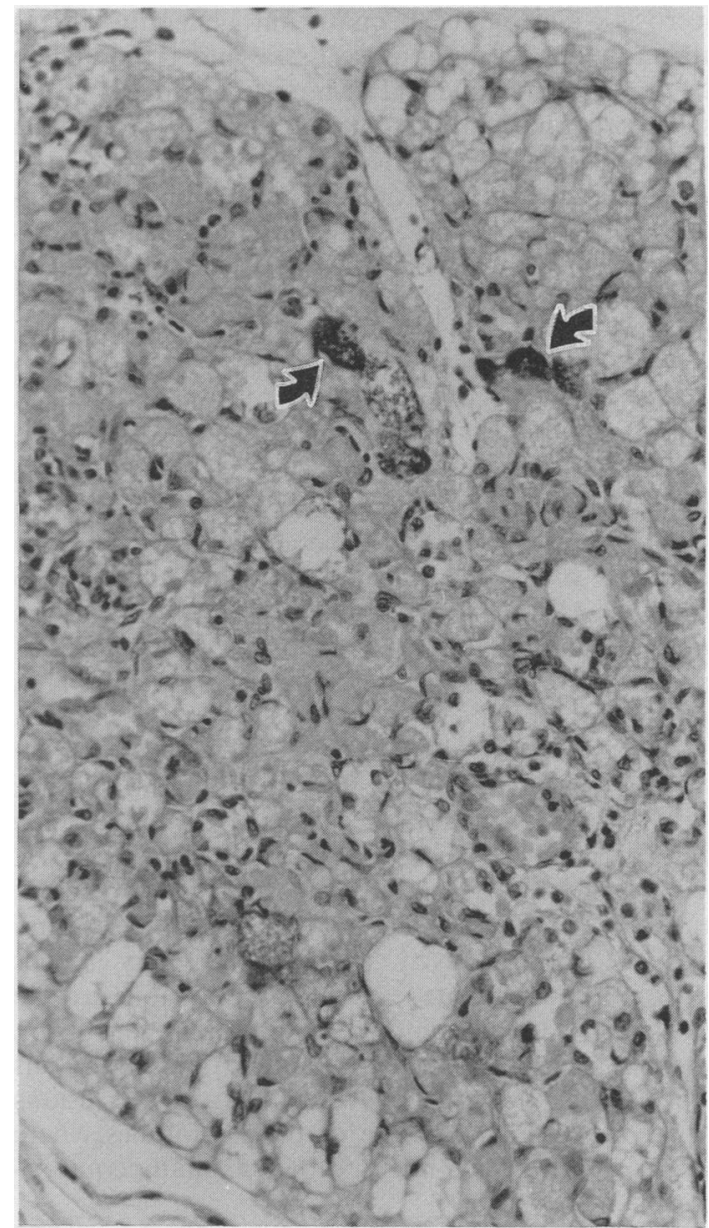

Fig 6 Poorly microvacuolated brown fat with focal calcification (arrows) and associated mild inflammatory reaction (Haematoxylin and eosin.) 
cytosis, and a stage of fibrosis. The presence of neutrophils implied a recent insult compatible with a preterminal event, whereas a longer standing lesion was suggested by the presence of macrophages. Similarly, dystrophic calcification and fibrosis were compatible with injury sustained several days previously. Granulomata were not seen, and this contrasts with the pattern seen in other types of panniculitis. ${ }^{78}$ This may reflect a different type of lipid to brown fat released on injury, or that the amount was too scanty to produce a noticeable reaction.

Panniculitis usually affects superficial white adipose tissue and has been described in several different clinical settings. ${ }^{2}$ A local vasculitis has been proposed as the basis of the Weber-Christian syndrome, ${ }^{9}$ but vasculitis was not a feature of the cases studied here. None of the infants had evidence of pancreatitis, another recognised cause of visceral fat necrosis. ${ }^{2}$ Scleraema neonatorum generally affects subcutaneous white adipose tissue and is limited to the period immediately after birth. The inflammation is also predominantly septal and it usually produces a lipogranulomatous reaction..$^{78}$

Pronounced intracytoplasmic acidophilic granularity and microvacuolation characterise the microstructure of brown fat. ${ }^{8}$ The cytoplasmic granularity corresponds ultrastructurally to an abundance of mitochondria that is related to oxidative metabolism. Age and environmental factors such as cold and nutrition influence the degree of brown fat microvacuolation which is inversely proportionate to its lipid content. ${ }^{10}$ The function of brown adipose tissue is closely related to thermal homeostasis in newborn infants and demands high metabolic activity and a high level of oxygen consumption. Each lobule also contains a rich plexus of capillary blood vessels; it has been estimated that at least one third of the surface of each fat depleted cell is in contact with an equal area of capillary wall. ${ }^{11}$

Reports relating to fat necrosis are usually of white adipose tissue whereas necrosis of brown fat has not been described previously. Of the many pathogenic factors known to be associated with superficial fat necrosis, none was readily apparent in the present study. The combination of a rich capillary plexus and high metabolic activity might conceivably render brown adipose tissue especially vulnerable to the effects of relatively minor degrees of hypoperfusion, possibly related to shock. Compatible with this hypothesis is the tendency for the microscopic lesions to occur within the centre of the fat lobules where vascular perfusion is likely to be maximally compromised.

Abnormal persistence of multilocular brown fat was shown at necropsy in cases of SIDS. ${ }^{1213} \mathrm{~A}$ similar finding among infants with cyanotic congenital heart disease suggested that chronic hypoxia might be an important factor. Consequently, the vulnerability of multilocular brown fat to infarction may extend into later months of infancy, and the occurrence of fat necrosis in our older infants could be explained on this basis.

The cause of SIDS is likely to be multifactorial, ${ }^{14}$ and the terminal pathophysiological events are barely understood. ${ }^{15}$ Although not specific to SIDS, these changes, probably ischaemic in nature, are likely to represent a specific cause of death and probably identify this group as a separate category within the syndrome. Severity and extent of fat necrosis were greater in the cases of SIDS compared with other causes of death, suggesting either a more severe degree of shock or an inability to mount effective compensatory mechanisms. Apart from the group with congenital heart disease, there were no factors in common which could have clarified the theory of shock among those with explained deaths.

\section{References}

1 Panush RS, Yonker RA, Dlesk A, Longley S, Caldwell JR. Weber-Christian disease. Analysis of 15 cases and review of the literature. Medicine 1985;64:181-91.

2 Case records of the Massachusetts General Hospital (Case 17-1982). N Engl J Med 1982;306:1035-43.

3 Milner RDG, Mitchinson MJ. Systemic Weber-Christian disease. J Clin Pathol 1965;18:150-6.

4 Hendricks WM, Ahmad M, Gratz E. Weber-Christian syndrome in infancy. Br J Dermatol 1978;98:175-86.

5 Beckwith JB. Discussion of terminology and definition of the sudden infant death syndrome. In: Bergman AB, Beckwith JB, Ray CG, eds. Sudden infant death syndrome. Washington DC: University of Washington Press, 1970:14-22.

6 Lever WF, Schaumburg-Lever G. Relapsing febrile nodular nonsuppurative panniculitis (Weber-Christian disease). In: Histopathology of the Skin. Fifth ed. Philadelphia. JB Lippincott, 1975:231-5.

7 Horsfield GI, Yardley HJ. Sclerema neonatorum. J Invest Dermatol 1965;44:326-32.

8 Katz DA, Huerter C, Bogard P, Braddock SW. Subcutaneous fat necrosis in the newborn. Arch Dermatol 1984;120:1517-8.

9 Reed RJ, Clark WH, Mihm MC. Disorders of the panniculus adiposus. Hum Pathol 1973;4:219-29.

10 Hull D. The structure and function of brown adipose tissue. $\mathrm{Br}$ Med Bull 1966;22:92-6.

11 Aherne W, Hull D. Brown adipose tissue and heat production in the newborn infant. J Pathol Bacteriol 1966;91:223-34.

12 Naeye R. Hypoxaemia and the sudden infant death syndrome. Science 1974;186:837-8.

13 Valdes-Dapena MAM Gillane MM, Catherman T. Brown fat retention in sudden infant death syndrome. Arch Pathol Lab Med 1976;100:547-9.

14 Emery JL. A way of looking at the causes of crib death. In: Tildon JT, Roeder LM, Steinschneider A, eds. Sudden infant death syndrome. Academic Press, London: 1983:123-32.

15 Farber JP, Catron AC, Krous HF. Pulmonary petechiae; ventilatory-circulatory interactions. Pediatr Res 1983;17: 230-3.

Requests for reprints to: Dr S Variend, Department of Histopathology, The Children's Hospital, Western Bank, Sheffield S10 2TH, England. 